Joan Cutting*

\title{
The In-Group Code Lexis
}

\begin{abstract}
This article provides a developmental description of the lexis used by an academic discourse community in formation. Casual conversations of six post-graduate students, native speakers of English, were recorded in the Applied Linguistics common room in Edinburgh University throughout the 1991-92 course. The central hypothesis was that as common knowledge of the course and shared interpersonal knowledge increase over time, there is an increase in the implicit vocabulary which forms the in-group code, and which depend heavily on the context for their meaning. This article discusses the gradability of contentfulness in lexis in topics about the course, analysing technical terms, proper nouns with metonymical meaning, limited range generic nouns, and general nouns and verbs. It discusses the implicitness of the lexical items that have a pragmatic meaning that only in-group members would understand, and suggests that, for an outsider, the implicitness can be associated with the impenetrability of the dialogue.
\end{abstract}

\section{Introduction}

If you overhear a group of people whom you do not know, you will often find that you can not understand what they were talking about. This article describes part of a study that asked the question "Why is listening in on other people's conversations so difficult when the speakers know each other well?' Examining the casual conversations of a group of students, the study aimed to discover what it is exactly that excludes outsiders who lack the shared knowledge of the group.

The hypothesis was that it is not only the shared knowledge that makes the conversations impenetrable but also the implicit way that in-group members refer to entities, situations, events etc. in that shared knowledge. The whole study tested the hypothesis that implicitness of the in-group

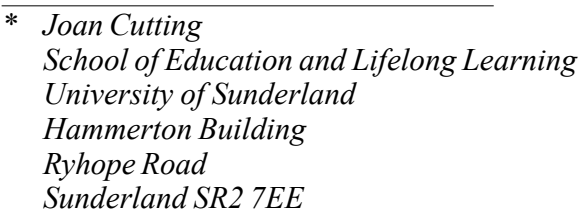

Hermes, Journal of Linguistics no. 28-2002 
60

code lies in the grammar, the lexis, the clause structure and the overall implied meaning not expressed in words. Cutting (2000) describes the development of implicit grammatical features: definite non-anaphoric personal ("he", "it", "they", as in "Did you go and see him then?", out of the blue, with no mention in the immediately preceding text of who "him" might refer to), and non-anaphoric demonstrative pronouns and adverbs ("this", "those", "now", "there", as in "That was a waste of time, wasn't it?", again with no previous mention of what "that" refers to). This article focuses on the part of the study that examined the lexical features, the vocabulary, of the in-group code.

To date, studies of the lexis of social groups compare strangers' and intimates' language as a product at a given time. The language of ingroup members has been found to contain elliptical elements particularly heavily dependent on common knowledge. Brown and Levinson (1978), describing strategies for claiming in-group membership, mention the use of in-group address forms and jargon. Gumperz (1982:131), in his discussion of contextualisation cues used by social groups, says, "exclusive interaction with individuals of similar background leads to reliance on unverbalised and context-bound presuppositions in communication". As he explains, contextualisation cues are "code or style-switching strategies, of formulaic utterances and other lexical options which affect the inferential process by recalling interpretative schemata or suggesting how message parts can be linked to create a thematic whole." (Cook-Gumperz and Gumperz, in Grimshaw 1994:381). Clark (1997:579) observes that associated with each community is a special mental lexicon, or "communal lexicon".

What is different about the present study is the fact that it hypothesised that implicitness increases with intimacy, and examined how the implicitness and impenetrability build up over time, how they develop gradually from the time when speakers first meet until the point at which they consider themselves to be members of an in-group. Taking an approach to discourse analysis based on pragmatics (Grice 1975, Leech 1983, Levinson 1983) and interactional sociolinguistics (Goffman 1963, Gumperz 1982, Tannen 1989), the study looked at how the in-group code developed as the number of group interactions grew over time. The aim of the study was therefore to use a longitudinal analysis, describing the language as a process. It was felt that different types of implicitness 
develop differently, and the study aimed to discover which parts of the language change first, and which later, and how.

Having described the development of the lexical elements, this article goes on to investigate how successfully the implicit code works for ingroup members, and whether it can cause communication to break down, and it also investigates the relationship between the lexical elements and the impenetrability of the conversations for outsiders. The hypothesis was that implicitness does not impede communication amongst in-group members, but that it does prevent outsiders from understanding.

The in-group studied was an academic discourse community, defined by Swales (1990) as a group whose members have common goals, intercommunication mechanisms, particular genres and specific lexis. Swales includes lexical choice as part of his definition of the academic discourse community, explaining that "somewhere down the line, ... understanding the rationale of and facility with appropriate genres will develop, control of technical vocabulary in both oral and written contexts will emerge" (1990:32). Kreckel (1981:36) found that one student group's language consisted of "a multitude of in-group codes, ... taking discipline or group-specific knowledge for granted".

The particular academic discourse community studied was that of students of the University of Edinburgh's MSc in Applied Linguistics (the study of real language and applications to teaching, translating and interpreting, speech therapy etc.). The MSc is a Master's level course, consisting of three terms of lectures (October to December, January to March, April to May) and a dissertation in the summer months. The students are strangers to each other when they arrive, form a close-knit group throughout the year, and then return home at the end of the course. The course attracts native speakers of English from Canada, Ireland, Scotland, England and Wales, and non-native speakers of English from Europe, Asia and Africa. In the 1991-92 course, there were 34 students, 16 of whom were native speakers of English, and they had an average age of 31. The study was based on the conversations of six native speakers of English in that year. Most social interaction took place in lunch hours and coffee breaks; most conversations occurred in the department common room or in a university cafeteria.

The main research questions of the present study that are presented in this article were: what is the exact nature of the in-group code lexis, to 
62

what extent does the choice of lexis depend on the topic, and how does the lexis evolve from the moment speakers first meet until the in-group is formed? The article aims to explore the co-existence of the formal, discipline-specific technical vocabulary along with the casual, vague form of reference that is the main interest. Describing vague language, Channell says,

\footnotetext{
"Hearers and readers need to draw on pragmatic information in order to identify the intended vague category. They use in particular: a) the surrounding linguistic context; b) the purpose of the text or conversation; and c) their world knowledge." (1994:143)
}

Leckie-Tarry suggests that the lowest degree of explicitness is to be found in the registers of casual conversations and the highest in the registers of formal written discourse (1995:133). Yet it was hypothesised in the study that the implicit language would contain elements of both written and spoken language, since the more the students read, the more elements of their reading creep in their speech.

The article ends with a discussion of the function of the in-group code, answering the question, 'Why do in-group members choose to refer to entities, situations, events in this implicit way?'. Cutting (2001) finds that the implicit use of language serves to express in-group membership and to show solidarity to group members.

\section{Method}

Spontaneous conversations were overtly recorded once a week in the first half of each of the three terms in the common room of the Applied Linguistics Department. Each day's recording lasted from 10 to 30 minutes; the total number of hours was seven. It was decided to focus on a small group of English native speakers to permit the researcher to become familiar enough with each of them to detect any tendencies caused by speakers' idiosyncrasies. The six 'recordees' were not told that they had been selected until the end of the course. Triangulation, in the form of questions on dialogues and a free discussion with the recordees, showed that they were a representative group of the MSc student body, and later impressionistic analysis of other MSc groups showed similar language features.

The 26,000 words of data was transcribed in discourse units, defined as stretches of talk uttered by one person that end with a falling intonation 
and have no pause of more than 0.5 seconds within them. Then the knowledge areas (defined below in section 3), the grammatical categories (see Cutting 1999), the lexical categories (defined and exemplified below in section 4) and functional features (macro-functions and speech acts, see Cutting 2001) were coded. Intercoder reliability of the coding system was checked by asking volunteers (students and staff in the Department of Applied Linguistics) to use the code to tag the lexis and label the functions in the samples of the data. The coded text was then analysed to find the densities of the elements and how they co-occurred with the other features (calculations were made of the average percentage of the lexical items out of all words and the average percentage of discourse unit containing each function out of all discourse units), and also to carry out qualitative interpretations.

To test the theory that implicit contextualisation cues can be responsible for an outsider being excluded from the in-group's dialogues, outsiders to the course were invited to listen to excerpts, say what the interlocutors were talking about (thus showing whether the dialogue was impenetrable to them), and answer comprehension questions focusing on the reference of specific language items (thus showing whether they could identify the referents of the implicit in-group code). There were three groups of outsiders. Group A were non-English teachers and non-linguists from the South of England. Group B were English teachers from Edinburgh who knew nothing of any DAL (Department of Applied Linguistics) MSc course. Group C were Edinburgh DAL MSc course students from previous years.

Subjects listened to four dialogue fragments, taken from the beginning of each of the three terms, each fragment lasting for 20-25 discourse units. Subjects wrote answers to one global question about the topic, and five specific questions about the referents of referring expressions and their implications: each focused on some aspect of the in-group code.

\section{Knowledge Areas}

Because this article contains a description of the way that increasing common knowledge over time affects the language and also the way that the topic area influences the language, the knowledge itself needs to be described. 
64

Two knowledge area (henceforth $\mathrm{K}$ area) categories were established: the non-course $\mathbf{K}$ area and the course $\mathbf{K}$ area. The non-course $\mathrm{K}$ area was the world outside the MSc course, including language teaching, university study, etc. as well as The University of Edinburgh (EU), The Department of Applied Linguistics (DAL) and The Institute for Applied Language Studies (IALS). On the other hand, the course K area was the 1991-92 MSc year itself: programme deadlines, specific tasks, study groups, particular books and articles, ways of referring to courses, students etc.

In the analysis of the data, each discourse unit was labelled according to the $\mathrm{K}$ area. The Kappa intercoder reliability test was done with two coders and gave a result of $46 \%$ for one coder and $75 \%$ for the other. This was considered satisfactory.

The analysis showed that the course $\mathrm{K}$ area topics occupy $43 \%$ of all the data. Each term has its own course/non-course balance, the change of topic reflecting a change of concern, depending on the events on the timetable. In the autumn term, when students follow basic core courses and get to know each other, non-course topics of language teaching and study are most frequent. In the spring term, when they select a number of option courses and feel a sudden increase in the pressure of work from their written examination and three projects, the course $\mathrm{K}$ area topics are most frequent. In the summer term, when, adapted to the pressure, they follow fewer courses, work more independently, and look to their future, both $\mathrm{K}$ areas occur.

\section{Lexical Categories}

\subsection{Definitions}

The lexical categories devised for the analysis of the data are based in part on categories of vagueness described in the literature. The study deals with vagueness in the sense of Ullman's (1962) generic words (bird) referring to classes of things, Crystal and Davy' (1975) dummy nouns expressing total vagueness (e.g.: thing), and Channell's (1994) vague "placeholder" words (e.g.: thingy and whatsisname). Halliday and Hasan (1976:274) say that general nouns are so vague that they are a "borderline case between a lexical and a grammatical item"; they are 
close to personal pronouns. Similarly, the general 'do' verb is on the borderline between the lexical verb and the substitute. General words are only part of the implicit language analysed in the study.

In the categorisation of nouns, there were two macro-groups: 'noncourse nouns' and 'course nouns' (see Figure 1), the latter being those that relate to activities and experiences in the course. The three volunteers who tested the code for intercoder reliability got the results $82 \%, 77 \%$ and $60 \%$ of agreement with the researcher, which suggests that the coding system is reliable.

Figure 1. Course noun model

\begin{tabular}{|ll|}
\hline Common & Proper \\
\hline Non-General & \\
-technical & -actual \\
-unique & -metonymical \\
-limited range & \\
General & \\
\hline
\end{tabular}

There are two main groups of course nouns: common or proper. In the common nouns group, there are general nouns and non-general nouns. The category general nouns contains lexical general nouns (eg: thing, stuff and people), as in:

(1) $03073 \quad$ BM I did em the literary // thing.

meaning 'literary question'. There are three non-general sub-divisions: technical, unique and limited range. Nouns are technical if they are intrinsically specialised terms independent of the context of the course. These are terms from linguistics and language teaching theory, such as diglossia, lexical syllabus, morphology and X-bar. Course nouns are unique if they are generalised nouns with specific pragmatic meaning, used to refer to intrinsic single components of the course, used in department organisation, mentioned the course handbook, etc., such as the dissertation, the portfolio and the examiner. Limited range course 
66

nouns are generalised nouns with specific pragmatic meaning, used to refer to an intrinsic class of components in the course. They are count nouns whose meaning is not expressed explicitly since they constitute the second noun of a two-word phrasal expression (Huddleston 1988:103) in which the first word (usually a nominal pre-head modifier) is understood. Examples are your book meaning 'your Syntax book' and that class meaning 'that Semantics class'.

Under the course proper noun heading there are two sub-divisions: the actual use and the metonymical use. In the actual use, the proper noun is used to refer to the writers, schools, etc. themselves. The course proper noun may be the name of writers (e.g.: Fasold), sciences and schools of thought (e.g.: Descriptivism), books and journal titles (e.g.: ELTJ), parts of Edinburgh University (e.g.: King's Buildings), members of staff and students (e.g.: $X Y$ ), and also students' spouses, partners and children (e.g.: Dave). The other course proper noun sub-division is the metonymical use, in which the noun refers elliptically to something other than the course/linguist named, something other than the literal meaning of the words used. As with the limited range nouns, these can be seen as one word of a two-word phrasal expression. In the case of the metonymical use, it is the second word that is understood. Proper nouns with metonymical use are MSc course names, such as Syntax meaning 'Syntax course exam question', and Language and Linguistics meaning 'Language and Linguistics option tutorial'. Linguists' names are used metonymically too: Brown and Miller meaning 'Brown and Miller's book', and Channell meaning 'Channell's paper'.

The verbs are not divided into course and non-course categories. There are just two categories: the "all verbs" one and the general 'do' verb one. Of interest for this study is the general 'do' verb category, which contains non-contentful verbs that depend pragmatically for their meaning on the text, such as do, make, have and happen (Cutting 2000; Halliday and Hasan 1976). These verbs can refer to an unidentified or unspecified process, as in What was she doing?, Nothing's happening and What am I to do?, and they are context-dependent. If, for example, a student says, What're you doing?, the listener knows that the speaker is asking 'What option courses are you taking?' and not 'What's your job?' These verbs also function as a transitive verb, as in do a book 
mean 'read a book' or 'write a book'; or do Peter meaning 'phone him' or 'give him his dinner' depending on the context.

\subsection{Analysis}

The hypotheses are based on impressionistic observation; the model of analysis is not an a-priori one. It seemed to the researcher, sitting in the common room casually observing the students in the spring term, that they used proper names and terminology a great deal. She surmised that this was a result of their reading and discussing thinkers and their thoughts, all of which had expanded their subject-specific vocabulary. In the summer term, she had the impression that the proper names and terminology were still there but there appeared to be more vague expressions as well. It was as if the students had 'relaxed into' their specialism and were not under so much pressure to inform and impress. Thus, the hypotheses were:

1) Over time, the density of non-general course nouns (diglossia, dissertation, book) increases.

2) Over time, the density of general nouns and verbs (thing, stuff, do) increases.

Central to the analysis of lexis in reference was the comparison between the $\mathrm{K}$ areas. It seemed logical to suppose that when the students talk about the course, they use a different lexis from that which they use when they are talking about the world outside the course. It was hypothesised that:

3) The course $\mathrm{K}$ area has more non-general course nouns (diglossia, dissertation, book) than the non-course $\mathrm{K}$ area.

4) The course $K$ area has more general nouns and verbs (thing, stuff, do) than the non-course $\mathrm{K}$ area.

The study investigated whether, because course topics contain more limited knowledge guaranteed to be known and in the mind of the hearer, the students could afford to be less explicit about what they were referring to.

Starting with the analysis of non-general course nouns, let us look at hypotheses 1) and 3). The test of hypothesis 1) showed that the density of non-general course nouns increases in both $\mathrm{K}$ area types, most dramatically in the course $\mathrm{K}$ area (see Figure 2). 
68

Figure 2. Percentage of non-general special course nouns out of all nouns

\begin{tabular}{|lcc|}
\hline & The non-course $\mathrm{K}$ area & The course $\mathrm{K}$ area \\
\hline The autumn term & 2.3 & 32.5 \\
The spring term & 5.4 & 43.9 \\
The summer term & 7.5 & 51.6 \\
\hline
\end{tabular}

The test of hypothesis 3) shows, not surprisingly, that the course K area dialogues have a greater density of non-general course nouns than the non-course $\mathrm{K}$ area. Figure 3 gives a picture of the difference between the course $\mathrm{K}$ area and the non-course $\mathrm{K}$ area.

The course $\mathrm{K}$ area has a high density of lexical items that have implicit meaning. The most dense of these are the limited range common nouns (classes of course component, e.g.: project) and the proper nouns (e.g.: Chomsky), and the latter show the greatest increase over the three terms. The density of the unique terms (single course components e.g.: the examiner) is lowest, because the number of nouns possible in the unique group is small anyway.

Limited range nouns refer to components of the course in such a general way that the meaning is implicit. The course component may be an organisational one, such as a "term" or a "group" as in:
(2) $\rightarrow$
$03010 \mathrm{BM}$
// No no you're in X's group I think.
$03011 \mathrm{NF}$
Oh yes sorry.
$03012 \mathrm{NF}$
I keep thinking you're X. 
Figure 3. Density of each non-general special course noun type out of all nouns

\begin{tabular}{|c|c|c|c|c|c|}
\hline The non-course $\mathrm{K}$ & & $\mathrm{Co}$ & & & Proper \\
\hline & & unique & limited & actual & metonymical \\
\hline The autumn term & 0.2 & 0 & 0 & 1.9 & 0 \\
\hline The spring term & 0 & 0 & 0.1 & 4.6 & 0 \\
\hline The summer term & 1.2 & 0.1 & 0 & 6.2 & 0 \\
\hline The Course K Are & & Cor & & & Proper \\
\hline & & unique & limited & actual & metonymical \\
\hline The autumn term & 2.6 & 0 & 18.3 & 10.6 & 1.8 \\
\hline The spring term & 3.6 & 1.7 & 9.1 & 15.3 & 14 \\
\hline The summer term & 3.3 & 0.4 & 17.6 & 24.5 & 5.8 \\
\hline
\end{tabular}

in which "group" refers to the "pre-tutorial group for discussion of tutorial tasks before the tutorial itself with a member of staff". The course component may be a piece of work, such as an "exercise" or a "project" as in:
(3) $\rightarrow$
$17002 \mathrm{CM}$
How's your project going?
17003 B M
I tried to write the introduction over the weekend.

in which the "project" is the third project in the course and specifically the one that $\mathrm{BM}$ is doing. The component may also be something that has been suggested to the students for reading, such as a "book" or a "paper", as in:
(4) $\rightarrow \quad 15194$ BM
// What about the article?
$15195 \mathrm{BM}$
I wasn't really using it.
15196 D M
I could quote from it actually.

Here, BM offers DM an "article", which, it would seem, they have both read and both need. In none of these examples is it necessary for the students to specify which "group", "project" or "article" is being referred 


\section{0}

to: the exact identity of the referent is implicit and in-group members know what the range of possible referents is limited to.

In the category of course proper nouns with their actual use, as in Chomsky referring to the man himself, the largest group is that which refers to linguists, books and journals, and sciences and schools of thought. An outsider to the course might be familiar with these, but only in-group members would know details such as what course option the linguist or school of thought is connected with, and what course task the books and journals were recommended for. This 'extra coating' of in-group knowledge on top of the conventional knowledge about the linguist, book and journal etc. makes even these words add to the implicitness and impenetrability of the code.

More implicit is the metonymical proper noun, which refers to course components without mentioning the component itself. Students use course names to refer to an exam question, a lecture, or, as in the next example, a tutorial:

(5) $\rightarrow \quad 0900 \mathrm{NF} \quad$ Are you going to Stylistics?

Students use the names of linguists to refer implicitly to theories or papers. In the following example:

(6) $\rightarrow \quad 08031$ AM $\quad$ Though though I haven't I haven't done any Chomsky. 08032 AM Probably a bit late // now.

08033 CM // Chomsky doubles up in Psycholinguistics.

on the first occasion, they are talking about revision of course material on his theories for the exam, and on the second, about information given in course lectures about his theories. It is not clear what "Psycholinguistics" means here: it could be "what we learned in the Psycholinguistics course". In the next example:
(7) $\rightarrow$
$15204 \mathrm{DM}$
I didn't like the Tolwood at all.
$15205 \mathrm{DM}$
I thought it was a bit (0.5) a bit much really. ((0.5))
$15206 \mathrm{BM}$
It wasn't er it wasn't reflected anywhere.

only an in-group member would know if they refer to a book, an article, a theory, etc.

Let us go on now to the discussion of general words. With regard to the general nouns part hypotheses 2) and 4), neither are confirmed. The density of general nouns rises in the spring term and then falls, and 
the course $\mathrm{K}$ area has a similar density to that of non-course $\mathrm{K}$ area dialogues. It is the grammar of the general noun that differentiates the course $\mathrm{K}$ area from non-course $\mathrm{K}$ area ones.

In the course $\mathrm{K}$ area, general nouns are more often introduced nonanaphorically with definite reference than they are in the non-course $\mathrm{K}$ area. This makes their meaning totally implicit in the course $\mathrm{K}$ area. In the following:

(8)

$$
\begin{aligned}
& 15041 \mathrm{CM} \text { Can't remember the last time I handed in anything late. } \\
& 15042 \text { DM (heh heh // heh heh) } \\
& 15043 \mathrm{CM} \quad / / \text { Usually it's three months early. } \\
& 15044 \text { DM (heh heh) Right. (8) } \\
& \rightarrow \quad 15045 \mathrm{DM} \quad \text { So I typed that thing up again after you'd gone. } \\
& 15046 \mathrm{CM} \quad \text { Oh yeah. }
\end{aligned}
$$

DM suddenly shifts topic using the general noun to refer to something that has not been mentioned before; it is possibly a questionnaire or a proposal for a project. The course $\mathrm{K}$ area general nouns usually point to specific referents in the context of background knowledge; the non-course $\mathrm{K}$ area more often have generic or situational reference (this thing). Example 9 is another example from the course $\mathrm{K}$ area:

$\begin{array}{ll}\text { (9) } 20046 \text { DM } & \text { There are a few things in ELTJ. (2.5) about it. (0.5) } \\ \text { 20047 DM } & \text { ((sniffs)) which are you know. } \\ \text { 20048 D M } & \text { There's not a lot though. (0.5) } \\ 20049 \text { D M } & \text { It's quite nice. } \\ \rightarrow \quad 20050 \text { BM } & \text { Did you see em X about that MSc thing? } \\ \text { 20051 DM } & \text { That's right. } \\ \text { 20052 D M } & \text { I'll go up and see if I can see it. }\end{array}$

Here, the referent of the general noun would be obscure to anyone lacking the shared interpersonal knowledge. Even the researcher had no access to what that MSc thing refers to.

All course nouns contribute in different ways to the implicitness of the course $\mathrm{K}$ area language. The meaning of technical nouns and the proper nouns with the actual use is not strictly speaking implicit, except that students give them extra meaning by using them in connection with specific course events. On the other hand, the unique and limited range common noun, the metonymical proper noun and the general noun do depend 
72

entirely on the context for their meaning; they are implicit contextualisation cues. The same goes for general verbs.

Turning now to the general verbs part of hypothesis 2), tests confirmed that the density of general 'do' verbs does increase. Taking all the data together, the density of general "do" verbs out of all verbs in the autumn term is $5.11 \%$, in the spring term is $5.6 \%$ and in the summer term is $6.8 \%$. A comparison of the non-course $\mathrm{K}$ area and the course $\mathrm{K}$ area confirms the verb part of hypothesis 4): the course $\mathrm{K}$ area has on average four times as many general "do" verbs.

Qualitative analysis of the course K area's general "do" verbs shows that $45 \%$ of them collocate with course nouns, which adds to the implicitness of a sentence because the meaning of the "do" verb depends on the meaning of another implicit lexical item. $17 \%$ have limited range course nouns as objects, as in (10) in which "do" means "answer an exam question on":

$(10) \rightarrow \quad 12221$ AM $\quad$ No I'd- I- s- I thought I had to - best to do the data questions first then you know // how much you've got for the essay.

$\begin{array}{ll}12222 \mathrm{CM} & \text { Then you know how // much time yeah. } \\ \rightarrow \quad 12223 \mathrm{AM} & \text { And I knew I was going to do one essay so. }\end{array}$

and (11), in which "do" means "taking" or "going to the classes":

$(11) \rightarrow \quad 20004$ BM $\quad$ I'm doing my option on discourse.

$13 \%$ of general "do" verbs have metonymical proper names as direct objects. In (12), the "do" verb means "work on the tutorial questions for":
$(12) \rightarrow \quad 04124$ BF $\quad$ Has anybody done their Syntax? ((1))
$04125 \mathrm{DM} \quad / /$ I did it yesterday.
04126 D M Oh that's what I was doing yeah.
$\rightarrow \quad 04127 \mathrm{BM} \quad$ // No I haven't looked at it yet.

In (13), "do" means "write an answer to the exam question":
$(13) \rightarrow \quad 12001$ AM $\quad$ So you didn't do the- the Grammar or the Semantics? 12002 CM No.
$\rightarrow \quad 12003 \mathrm{CM} \quad$ I studied the Semantics quite a bit and then I didn't do it. 12004 AM Yeah.

In (14), "do" means "take the option course": 

$(14) \rightarrow \quad 15135$ BM $\quad$ You do you do Language Planning don't you?
15136 DM Yeah.

Only in-group members would know the exact meaning of these verbs. $11 \%$ of general "do" verbs combine with general nouns. The implicitness seems most impenetrable when both the verb and the noun are at the extreme end of non-contentfulness. In the following:

$\begin{array}{ll}03073 \mathrm{BM} & \text { I did em the literary // thing. } \\ 03074 \mathrm{BM} & \text { The literary language one. } \\ 03075 \mathrm{AM} & \text { // I did the I did the business one. }\end{array}$

if the "thing" is a tutorial task question, then "doing" the "thing" might mean "answering the questions" in a task. In (16), students compare how each of them has revised for the exam:

(16) $10069 \mathrm{CM} \quad$ No I've done all the people.

Here the "people" would appear to be linguists; thus to "do" the "people" must mean to "prepare to answer the question" about their work.

In summary, as far as the lexis of the in-group is concerned, as hypothesised, there are changes over time and differences between the $\mathrm{K}$ areas. In the course $\mathrm{K}$ area, the increase in implicit lexis is more dramatic than that of the non-course $\mathrm{K}$ area. The choice of lexis is therefore as much a reflection of the topic itself as a result of time and accumulating interactions.

Over time, non-general course nouns and general 'do' verbs increase in all the data. Thus the subject specific nouns increase at the same time as the implicit informal verbs. It can be said that lexical implicitness does indeed increase, in that the general 'do' verbs collocate with the subject specific nouns, such as limited range course nouns and general nouns, that only gain their full meaning from the course.

In the course $\mathrm{K}$ area dialogues, there is a greater density of metonymical proper nouns, unique course nouns and limited range nouns than in noncourse topics, and four times as many general "do" verbs (collocating with the heavily context dependent nouns) as in non-course topics.

\section{Impenetrability}

The introduction to this article raised the question 'Why is eavesdropping so difficult when the speakers know each other well?', explaining that 


\section{4}

the study aimed to discover what it is that excludes outsiders to the ingroup. The next part of this article describes how successfully the code functions for in-group members, and examines the relationship between the implicitness of the lexical items and the impenetrability for outsiders.

\subsection{In-group member confusion}

As is natural in casual conversation, there is sometimes a hitch or temporary halt in the flow of communication as the students speak. $52 \%$ of the hitches in the data are referential, caused by the speaker miscalculating the context that is in the interlocutor's mind and not providing enough explicit information for them to identify the referent. As Wardhaugh comments, "We may be led astray by the imprecision of certain very common words, words whose meaning can be determined only in relation to the contexts in which they are used" (1985:37).

$63 \%$ of these referential hitches occur in the non-course $\mathrm{K}$ area: the non-course $\mathrm{K}$ area language contains twice as many hitches as the more implicit course $\mathrm{K}$ area. Speakers almost always use the implicit in-group code in the course $\mathrm{K}$ area efficiently, therefore, but very occasionally the lexis can be so vague that interlocutors have to check whether they have understood. It is the metonymical proper noun and the limited range noun that feature most often in hitches. In

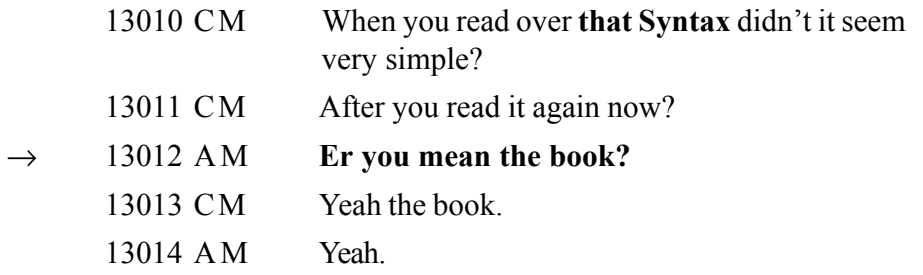

the metonymical proper noun "that Syntax" could have meant, as it does on other occasions, "tutorial task", "an option's material for the exam", "exam question" or "all that has been studied from lecture notes and articles and books". A limited range noun is at the centre of the following hitch:

(18) $07017 \mathrm{BF} \quad$ You've got a task to do with one (0.5) w it h one other person. 


\begin{tabular}{|c|c|c|}
\hline & $07018 \mathrm{BF}$ & $\begin{array}{l}\text { It's been the task - the whole task has been } \\
\text { divided up between the group. }\end{array}$ \\
\hline & $07019 \mathrm{NF}$ & Yes. \\
\hline$\rightarrow$ & $07020 \mathrm{BM}$ & What this one? \\
\hline & $07021 \mathrm{BF}$ & // No. \\
\hline & 07022 BM & // No. \\
\hline$\rightarrow$ & $07023 \mathrm{BM}$ & What are we talking about? \\
\hline & $07024 \mathrm{BF}$ & To // day's. \\
\hline & $07025 \mathrm{BM}$ & // Today's. \\
\hline
\end{tabular}

$\mathrm{BM}$ is feeling the pressure of the many tasks and has lost track of the one in question.

As part of a triangulation interview, the six recordees themselves listened to some of their recordings and answered questions about topic and referents. As expected, they had no difficulties at all.

In conclusion, half the hitches in all the data are referential, and of those hitches, only a third occur in the course $\mathrm{K}$ area. The parts of the lexis that very occasionally cause hitches are the metonymical proper noun and the limited range common noun. That is to say, the lexis of the in-group code works efficiently most of the time; members know what each other are referring to, however vague or implicit the word, because they share the knowledge and it is generally present in their minds.

\subsection{Outsider exclusion}

The Method section of this article explained that there were three groups of outsiders and four dialogue fragments that they listened to. We can now define these in terms of $\mathrm{K}$ area. Group A, the non-English teachers and non-linguists from the South of England, and Group B, the English teachers from Edinburgh who knew nothing of any DAL (Department of Applied Linguistics) MSc course but had non-course knowledge. Group $\mathrm{C}$, Edinburgh MSc course students from previous years and members of the discourse community of DAL MSc students past and present, could be said to have course knowledge. Two of the dialogues (identified as 1 and 4) were from the non-course $\mathrm{K}$ area, and the other two (identified as 2 and 3 ) from the course $\mathrm{K}$ area.

There did appear to be some relationship between implicitness and impenetrability. The test showed that the closer the group of hearers is to 


\section{6}

the 1991-2 MSc course, the more often they understand both topic and referring expressions (see Figure 4). Group B's knowledge was closer to course K area than Group A's, in that they knew Edinburgh and language teaching. A t-test shows that the difference between the groups' test scores is significant $(\mathrm{t}=2.68, \mathrm{df}=19, \mathrm{p}=0.015)$. It was also found that the ability to understand the topic is sometimes associated with the ability to understand the referring expressions (see Figure 5); the value of the correlation coefficient for answers to questions on the dialogue topic and questions on the reference of particular expressions for the four dialogues together is 0.590 , which is significant at $\mathrm{df}=28$, alpha $=0.05$ (one-tailed test). It was found, however, that failure to understand language details only makes course-related topics impenetrable; non-course topics can be understood even when all the language details are not understood).

Table 4. Mean of correct answers for topic knowledge and reference knowledge questions

\begin{tabular}{|lcc|}
\hline Subjects & $\begin{array}{c}\text { topic knowledge } \\
\text { (total } 4 \text { questions) }\end{array}$ & $\begin{array}{c}\text { reference knowledge } \\
\text { (total 20 questions) }\end{array}$ \\
\hline Group A & 2.4 & 11.1 \\
Group B & 3.2 & 13.6 \\
Group C & 4.0 & 17.2 \\
\hline
\end{tabular}

Table 5. Correlation between topic knowledge scores and reference knowledge scores

\begin{tabular}{|lccc|}
\hline & Group A & Group B & Total \\
Dialogue 1 & -0.409 & -0.236 & -0.098 \\
Dialogue 2 & -0.524 & -0.096 & -0.135 \\
Dialogue 3 & 0.602 & 0.390 & $0.482^{*}$ \\
Dialogue 4 & -0.121 & 0.631 & 0.217 \\
Dialogue 1, 2, 3 and 4 & 0.487 & 0.300 & $0.590^{*}$ \\
\hline
\end{tabular}


Qualitative analysis showed that groups A and B had difficulties with a wide range of lexical items within the special course noun category, which suggests that they are outsiders to the discourse community of DAL MSc students. The most frequent wrongly answered questions were ones about the metonymical proper nouns and limited range nouns, and the lack of understanding of these affected the understanding of the whole topic. Answering questions on one dialogue, for example, the subjects who did not know that the limited range noun "group" refers specifically to the "pre-tutorial study group" and simply suggested that its referent is "a group of students", could not appreciate the topic. They suggested that the speakers are discussing "a planned trip somewhere" or "filling in time ... not much content", when the topic could have been stated as "Who is in whose tutorial group" while the students are settling down to work on their tutorial task. Answering questions on another the course $\mathrm{K}$ area dialogue, the subjects who did not know that the metonymical proper noun "Psycholinguistics" refers to the course by this name rather than the field of study itself, or that the term "Chomsky" refers not to the man himself but to his theories, could not appreciate that topic of the dialogue could be phrased as "What AM and CM studied for the exam". They suggested that the topic was "Chomsky" or "Psycholinguistics, whatever they are".

Group C subjects got nearly all the answers right. They showed an appreciation of the full implications of referring expressions in the course K area dialogues: they rightly identified the "groups" as "pre-tutorial study groups", and "Psycholinguistics" as a "core course" for example. This suggests that they were indeed members of the DAL MSc discourse community.

The term "in-group members", however, must be reserved for members of one particular MSc course. Their code includes names of student members and their families (e.g.: "Dave"), and it may have special names for staff members (e.g.: "Fergey") and options (e.g.: "Sla"). Members use metonymical proper and limited range nouns to refer to particular entities within their own course (e.g.: "your Syntax", "any Chomsky", "that group" and "the project") and non-anaphoric general nouns (e.g.: "the thing") whose specific reference can be understood only those with knowledge of that particular course and the interlocutor. 


\section{Conclusion}

This study analysed lexis from the point of view of contentfulness and implicitness. The in-group code used in the student common room contains a mixture of the formal academic terms of lectures and linguistics literature, along with the informal vague language of casual conversations.

This article contributes a developmental, longitudinal dimension to the literature on in-group codes, showing the process of the code formation. The study shows that the choice of lexis is as much a reflection of the topic itself as a result of time and accumulating interactions. It is in dialogues on course topics that the density of in-group lexis grows with increasing knowledge over time. These dialogues necessarily contain technical terms and proper nouns, but they also have the more implicit unique and limited range nouns, metonymical proper nouns, and general "do" verbs, which add to the implicitness of the in-group code, especially when they collocate with each other.

It is possible that these findings could be generalised to extend to other discourse communities, such the community of translators and interpreters, the community of computer anoraks, the community of music lovers, etc. This would be an interesting area of research to continue further.

Most lexical choice has a social function. As far as the function of the lexical contextualisation cues is concerned, it could be said that the students use them because it is convenient for them: they are obeying the cooperative maxim of quantity (Grice 1975). The proper nouns and vague words are all that are needed; they are a form of shorthand that lets them communicate easily. They are a natural product of in-group membership and members use them unconsciously.

On the other hand, as Widdowson (1993) suggests, each social group "closes off" the group through its choice of lexis. Tannen (1989:23) observes that "the more work ... hearers do to supply meaning, the deeper their understanding and the greater their sense of involvement with both text and author". It may be that the students make a conscious choice to refer in an implicit way in order to claim in-groupness and intimacy. As Halliday and Hasan say, general nouns express "interpersonal meaning" and "a particular attitude on the part of the speaker" (1976:276). Brown and Levinson (1978) say that in-group jargon and local terminology is used by a speaker to claim in-group membership with the hearer. 
Specialised vocabulary from a permanent collocational environment can be used by members of in-groups to express solidarity: Atkinson (1981) discovered that medical students learned medical jargon and in-group language as part of their socialisation process. The ability to use the terminology correctly was one that developed over time but the conscious choice to use it in casual conversations was related to the desire for ingroup membership.

It is possible that speakers in the present study consciously choose to use technical terms and proper nouns to claim in-group membership. The in-group members give the formal language of their specialism their own extra implicit meaning, when they use the metonymical function. There may be an element of "We know how to use terms and names because we're Applied Linguists, aren't we? And we know we mean something more than just the literal meaning of the words themselves, don't we?"

It may also be that they can make a conscious choice to speak vaguely using limited range nouns, general nouns and general verbs, in order to express in-group membership and in-the-same-boatness. The lack of precision also suggests that there is a desire to establish a relaxed, informal relationship between speakers. Here, it may be a case of "We won't bother to name these things too carefully: we know what we're talking about because we're in-group members, aren't we?" Again, further research might reveal that this applies to all discourse communities and social groups.

\section{Acknowledgement}

I should like to thank Professor Alan Davies for his guidance and Dr. Hugh Trappes-Lomax, for his interest and criticism. I should also like to thank the other members of DAL and IALS who offered advice and participated in the intercoder reliability test or the impenetrability test. I am, of course, very grateful to the six recordees themselves, whose casual conversations constitute my database.

\section{References}

Atkinson, P. (1981). The Clinical Experience. Hampshire: Gower Publishing Company.

Brown, G. \& Yule, G. (1983). Discourse Analysis. Cambridge: Cambridge University Press. 


\section{0}

Brown, P. \& Levinson, S. (1978). Politeness. Cambridge: Cambridge University Press. Channell, J. (1994). Vague Language. Oxford: Oxford University Press.

Clark, H. H. (1997). 'Dogmas of Understanding'. Discourse Processes, 23, 567-598 Ablex Publishing Corporation

Cook-Gumperz, J. \& Gumperz J. J. (1994). The Politics of a conversation: conversational inference in discussion in What's Going on Here?: Complementary Studies of Professional Talk Grimshaw, Allen D. (ed) New Jersey: Ablex

Crystal, D. \& Davy, D. (1975). Advanced Conversational English. London: Longman.

Cutting, J. (2000). Analyzing the Language of Discourse Communities. Elsevier Science: Oxford.

Cutting, J. (1999). 'The Implicit Grammar of the In-Group Code' Applied Linguistics Vol.20/1: 179-202. Eds. M. McCarthy and J.P. Lantolf. Oxford University Press: Oxford

Cutting, J. (2001). 'Speech Acts and the In-group' Journal of Pragmatics. Ed. J.L. Mey et al. Elsevier: Amsterdam

Goffman, E. (1963). Behaviour in Public Places. New York: Free Press.

Grice, P. (1975). Logic and Conversation. In P. Cole and J. Morgan (eds.) Syntax and Semantics 3. New York: Academic Press.

Gumperz, J. (1982). Discourse Strategies. Cambridge: Cambridge University Press.

Halliday, M. \& Hasan, R. (1976). Cohesion in English. London: Longman.

Huddleston, R. (1988). English Grammar an Outline. Cambridge: Cambridge University Press.

Kreckel, M. (1981). Communicative Acts and Shared Knowledge in Natural Discourse. London: Academic Press.

Lakoff, G. (1972). Hedges: A study in meaning criteria and the logic of fuzzy concepts. In Chicago Linguistic Society Papers. Chicago: Chicago Linguistic Society.

Leckie-Tarry, H. (1995). Language and Context: A Functional Linguistic Theory of Register. London: Pinter.

Leech, G. (1983). Principles of Pragmatics. New York: Longman.

Levinson, S. (1983). Pragmatics. Cambridge: Cambridge University Press.

Lyons, J. (1977). Semantics. Cambridge University Press.

Swales, J. (1990). Genre Analysis. Cambridge: Cambridge University Press.

Tannen, D. (1989). Talking Voices. Cambridge: Cambridge University Press.

Ullman, S. (1962). Semantics. Oxford: Blackwell.

Wardhaugh, R. (1985). How Conversation Works. Oxford: Basil Blackwell.

Widdowson, H.G. (1993). Peter Strevens Memorial Lecture. Unpublished paper in IATEFL 27th. International Annual Conference, University College of Swansea. 